\title{
Association of autoantibodies to filaggrin with an active disease in early rheumatoid arthritis
}

\author{
L Paimela, T Palosuo, K Aho, M Lukka, P Kurki, M Leirisalo-Repo, R von Essen
}

Orton, Invalid

Foundation, Helsinki, Finland

L Paimela

National Public Health Institute, Helsinki,

Finland

T Palosuo

K Aho

M Lukka

United Laboratories Ltd, Helsinki, Finland

P Kurki

Division of

Rheumatology,

Department of

Medicine, Helsinki

University Central

Hospital, Helsinki,

Finland

M Leirisalo-Repo

Department of Microbiology, Boden Hospital, Boden,

Sweden

$\mathrm{R}$ von Essen

Correspondence to:

Dr L Paimela, Orton, Invalid Foundation, Tenholantie 10,

FIN-00280 Helsinki, Finland

leena.paimela@invalidisaatio.fi

Accepted 7 June 2000

\begin{abstract}
Objective-To evaluate the clinical significance of antifilaggrin antibodies (AFA) measured by an enzyme linked immunosorbent assay (ELISA) in serial specimens from patients with recent onset rheumatoid arthritis (RA).

Methods-Filaggrin was purified from human skin and used as an antigen in ELISA. The AFA test was applied to five serial specimens from 78 patients with recent onset $R A$ followed up for three years. Rheumatoid factor (RF) had been measured earlier from the same samples by quantitative immunoturbidimetry.

Results-The mean AFA level was highest at entry (54\% positive), followed by a statistically significant decline at six months and a slight increase at three years. AFA were persistently positive in 23 patients and persistently negative in 28 patients. Eleven of the latter patients were persistently negative for RF. At study entry AFA levels correlated to some degree with RF levels. In general, raised AFA levels at entry were associated with an active and treatment resistant disease, but they did not predict radiological progression.
\end{abstract}

Conclusions-The test for AFA has potential for an additional immunological test for $\mathbf{R A}$.

(Ann Rheum Dis 2001;60:32-35)

Rheumatoid arthritis (RA) features several different autoantibodies, ${ }^{1}$ some of which are specific enough to serve as diagnostic and prognostic markers. ${ }^{2}$ Rheumatoid factor (RF) and two closely associated antibodies, antikeratin antibody (AKA) and antiperinuclear factor (APF), may even precede the onset of $\mathrm{RA}^{2}$ and at all events, most patients who produce these antibodies are positive already at the initial presentation of clinical symptoms. ${ }^{3-5}$ Thus these antibodies are not secondary manifestations of inflammation or tissue destruction.

The detection of AKA and APF is based on indirect immunofluorescence techniques, in which the substrates are not standardised. Technical difficulties have limited the use of these tests in clinical work. Both these antibodies are directed against proteins closely related to human epidermal filaggrin. ${ }^{67}$ We have described a method of purifying filaggrin from human skin and using it in an enzyme linked immunosorbent assay (ELISA) to measure antifilaggrin antibodies (AFA). ${ }^{8}$ Recently, AFA have been detected by immunoblotting on human semipurified or purified filaggrin. ${ }^{910}$
Also, synthetic peptides containing reactive antigenic sites of filaggrin have been used in ELISA. ${ }^{11}$ One of the immunoblotting studies showed a correlation between AFA and AKA, ${ }^{9}$ whereas the other showed a very low frequency of positive reactions for AFA. ${ }^{10}$ The test based on synthetic peptides showed a fairly good correlation with $\mathrm{APF}{ }^{11}$

We earlier measured RF by quantitative immunoturbidimetry in serial specimens from patients with recent onset RA. ${ }^{12}$ AFA have been shown to be specific serological markers in RA. In this study we investigated antifilaggrin ELISA on these patients.

\section{Patients and methods}

PATIENTS

Seventy eight consecutive patients (63 women, 15 men) with early RA satisfying the American Rheumatism Association (ARA) 1987 classification criteria were included in the study. At entry, the mean age of the patients was 43.5 years (range 19-65) and the mean duration of symptoms was 7.6 months (range $2-12$ ). None of the patients had received any disease modifying antirheumatic drug (DMARD) treatment before entry into the study. Intramuscular gold was started in 63 patients, sulphasalazine in 12, and hydroxychloroquine in three. Three patients used concomitant low dose prednisone (5-7.5 mg daily).

Clinical and laboratory assessment of disease activity included Ritchie articular index, number of swollen joints, morning stiffness, pain by the visual analogue scale, disease activity score (DAS), ${ }^{13}$ erythrocyte sedimentation rate (ESR), and $\mathrm{C}$ reactive protein (CRP) at entry, and at $6,12,24$, and 36 months.

Radiographs of hands and feet were taken at entry to the study and thereafter annually during the follow up. The $x$ rays were evaluated by the method of Larsen et al. ${ }^{14}$

\section{LABORATORY METHODS}

Blood samples for the determination of AFA and for RF were taken at entry and at $6,12,24$, and 36 months (during 1986-91). All serum samples were stored at $-20^{\circ} \mathrm{C}$ until analysed.

Filaggrin was purified from human epidermis as described earlier. ${ }^{8}$ Briefly, epidermis was cleaved from dermis by incubation at $56^{\circ} \mathrm{C}$ in $10 \mathrm{mM}$ potassium phosphate buffer, $\mathrm{pH} 7$.

The epidermal layer was peeled off, homogenised in a mortar, sonicated, centrifuged, and delipidated. The extracted proteins were chromatographed in reverse phase high performance liquid chromatography. Fractions containing filaggrin were identified in immunoblotting by monoclonal AFA, pooled, and sub- 


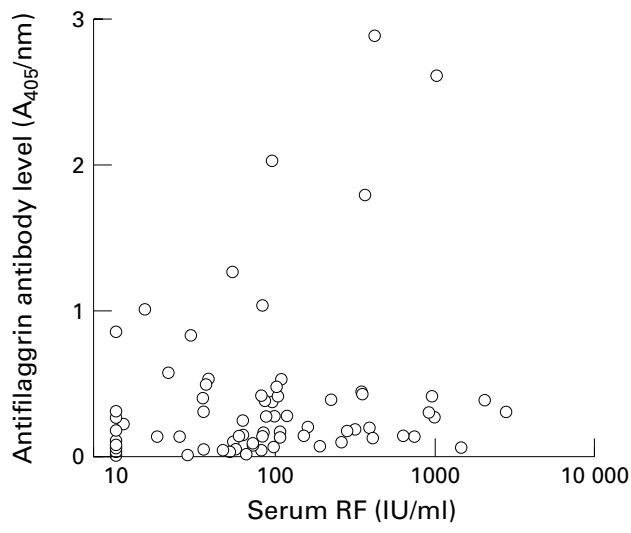

Figure 1 Correlations between antifilaggrin antibody and rheumatoid factor (RF) levels at entry to the prospective study in 78 patients with early rheumatoid arthritis.

jected to gel filtration and again to reverse phase chromatography. The identity and purity of the protein were further confirmed with tryptic digestion, peptide separation, amino acid sequencing, and mass spectrometric analysis of the formed peptides. The yield of purified filaggrin was of the order of $50-100 \mu \mathrm{g}$ from each gram of epidermis (wet weight).

ELISA for AFA was performed as described in detail elsewhere. ${ }^{8}$ Briefly, microtitre plates (Nunc, Roskilde, Denmark) were coated with filaggrin $(3 \mu \mathrm{g} / \mathrm{ml}$ in $50 \mathrm{mM}$ carbonate buffer, $\mathrm{pH}$ 9.6) and post-coated with $1 \%$ human serum albumin. Patient and control serum samples were diluted 1:500 in duplicate, and binding of IgG class antibodies to solid phase filaggrin was demonstrated by alkaline phosphatase conjugated, $\gamma$ chain-specific antihuman IgG antibodies. Cut off levels for positivity were determined on the basis of results of serum samples from 100 middle aged (40-65 years) blood donors. Five subjects had an optical density value $\geqslant 0.15$, which was taken as the cut off point for positivity. Another control series comprised 30 healthy subjects with the same age distribution as the patients and whose serum samples had been collected and stored identically. For these controls, mean $+3 \mathrm{SDs}$ corresponded to 0.15 optical density units. Interassay coefficient of variation of the method was 3\% for a high positive reference serum and $8 \%$ for a low positive serum.

A Kone specific automated clinical chemistry analyser (Kone Instruments, Espoo, Finland) was used for immunoturbidimetric measurement of RF and a modified assay using chemical inactivation of $\mathrm{C} 1 \mathrm{q}$ with polyvinyl sulphonate was used as previously described. ${ }^{15}$ When this method was used, 381/403 healthy subjects $(95 \%)$ had an $\mathrm{RF}<20 \mathrm{IU} / \mathrm{ml},{ }^{15}$ which was taken as the cut off point for positivity. According to the manufacturer, standards in the test kit had been calibrated against the WHO standard serum.

To eliminate possible intertest error, all specimens from each patient were always tested on the same occasion.

STATISTICAL METHODS

Differences between groups were analysed with the Wilcoxon test for paired data and the
Mann-Whitney test for unpaired data. Correlations were calculated with Spearman's correlation coefficient test. The area under the curve (AUC) was used as a summary measure to integrate serial assessments of disease activity and AFA levels (at months 0, 6, 12, 24, and 36). ${ }^{16}$

The radiographic progression (delta Larsen) was measured as the absolute difference between total Larsen scores at month 0 and 36 months.

\section{Results}

Figure 1 depicts the quantitative correlation between RF and AFA levels at entry $\left(r_{s}=0.30\right.$, $\mathrm{p}=0.001)$. Thirty six patients were positive and 13 patients were negative in both tests. Twenty three patients were positive only for RF and six patients only for AFA. Thus 58/78 (76\%) of the patients were RF positive and 42/78 (54\%) were AFA positive. Some patients strongly positive for RF were AFA negative and vice versa. The Spearman rank correlation between the two tests was $0.30(\mathrm{p}<0.01)$.

The mean AFA level was highest at study entry, followed by a significant decline at six months $(p=0.001)$ (table 1). Some increase was noted at three years. AFA were persistently positive in 23 patients, persistently negative in 27 patients, and the results varied in 28 patients ( 13 from positive to negative, 5 from negative to positive, and 10 varying). In many instances the changes were borderline. Yet in 10 instances a change of $\geqslant 0.3$ optical density units was noted. In three of these patients the test reverted from negative to positive; these patients can thus be regarded as definite late seroconversions.

RF was persistently positive in 17 patients, persistently negative in 13 patients and the results varied in 48 patients. Of the 17 patients persistently positive for RF, AFA were persistently positive in 10 patients and persistently negative in one patient; the results varied in six patients. Of the 13 patients persistently negative for RF, AFA were persistently negative in 10 patients and the results varied in three patients. Owing to the more frequent reversal of RF from positive to negative, as many as 15 patients were AFA positive but RF negative at six months. At three years, there were only seven such cases.

To look for correlations of the AFA levels with the clinical parameters, AFA levels at entry were divided into three tertiles and patients belonging to the lowest tertile and the highest tertile were compared. Table 2 shows that patients belonging to the highest tertile

Table 1 Antifilaggrin antibody level $\left(A_{405} n m\right)$ in the follow up specimens

\begin{tabular}{llll}
\hline Months & Mean & Median & p Value \\
\hline 0 & 0.351 & 0.163 & 0.001 \\
6 & 0.265 & 0.096 & 0.32 \\
12 & 0.262 & 0.101 & 0.16 \\
24 & 0.258 & 0.091 & 0.07 \\
36 & 0.295 & 0.115 & \\
\hline
\end{tabular}


Table 2 Mean (median) clinical, laboratory, and radiological data of patients with initially highest $(n=25)$ and lowest tertile distribution $(n=26)$ of antifilaggrin antibody (AFA)

\begin{tabular}{|c|c|c|c|}
\hline Index & $\begin{array}{l}\text { Lowest tertile } \\
\text { of AFA }\end{array}$ & $\begin{array}{l}\text { Highest } \neq \text { tertile } \\
\text { of } A F A\end{array}$ & $p$ Value \\
\hline \multicolumn{4}{|c|}{$\mathrm{ESR}^{\star}(\mathrm{mm} / 1 \mathrm{st} \mathrm{h})$} \\
\hline 0 years & $30.6(23)$ & $36.8(26)$ & 0.35 \\
\hline 3 years & $13.8(10)$ & $24.3(15)$ & 0.11 \\
\hline \multicolumn{4}{|c|}{$\mathrm{CRP}^{\star}(\mathrm{mg} / \mathrm{l})$} \\
\hline 0 years & $12.8(5)$ & $28.5(18)$ & 0.03 \\
\hline 3 years & $6.7(2)$ & $14.3(6)$ & 0.13 \\
\hline \multicolumn{4}{|c|}{ Ritchie index } \\
\hline 0 years & $9.2(7)$ & $10.5(9)$ & 0.45 \\
\hline 3 years & $2.3(1)$ & $4.9(2)$ & 0.03 \\
\hline \multicolumn{4}{|c|}{ Number of swollen joints } \\
\hline 0 years & $3.8(3)$ & $5.2(3)$ & 0.41 \\
\hline 3 years & $1.5(0)$ & $3.0(1)$ & 0.02 \\
\hline \multicolumn{4}{|c|}{ Morning stiffness (min) } \\
\hline 0 years & $135.0(120)$ & $130.7(60)$ & 0.47 \\
\hline 3 years & $21.6(0)$ & $54.4(15)$ & 0.005 \\
\hline \multicolumn{4}{|c|}{$\operatorname{VAS}^{\star}(\mathrm{cm})$} \\
\hline 0 years & $2.9(2)$ & $2.7(2)$ & 0.73 \\
\hline 3 years & $0.7(0)$ & $1.8(1)$ & 0.03 \\
\hline \multicolumn{4}{|l|}{$\mathrm{DAS}^{\star}$} \\
\hline 0 years & $3.1(2.9)$ & $3.2(3.3)$ & 0.54 \\
\hline 3 years & $1.6(1.5)$ & $2.3(2.1)$ & 0.02 \\
\hline \multicolumn{4}{|c|}{ Larsen's score } \\
\hline 0 years & $3.2(0)$ & $5.7(4)$ & 0.02 \\
\hline 3 years & $15.8(12)$ & $23.2(20)$ & 0.16 \\
\hline
\end{tabular}

${ }^{\star} \mathrm{ESR}=$ erythrocyte sedimentation rate; $\mathrm{CRP}=\mathrm{C}$ reactive protein; VAS = visual analogue scale; DAS $=$ disease activity score. †Cut off level $\leqslant 0.118$

$\ddagger$ Cut off level $\geqslant 0.295$.

had significantly higher CRP concentration and Larsen's score at entry to the study. After three years, significant differences were noted in the Richie index, number of swollen joints, length of morning stiffness, visual analogue scale of pain, and DAS, with patients in the highest tertile having more severe disease.

There were weak correlations between AUC $\mathrm{AFA}$ and AUC ESR ( $\left.r_{s}=0.24, \mathrm{p}=0.05\right)$, and between AUC AFA and AUC DAS $\left(r_{s}=0.24\right.$, $\mathrm{p}=0.05)$. No significant correlations were found between AUC AFA and AUC other variables of disease activity or Larsen score (data not shown).

The baseline AFA levels did not correlate with the radiographic progression (delta Larsen $)\left(r_{s}=0.15, \mathrm{p}=0.17\right)$.

\section{Discussion}

We compared the behaviour of quantitative tests for AFA and RF in serial specimens from patients with early RA using assay conditions in which cut off points for positive reactions were adjusted to the same specificity level for both tests. It was found that the level of these two antibodies fluctuated considerably during the three years of follow up.

Earlier studies on serial APF and AKA measurements showed that positivity in these tests is fairly stable, though conversions from positive to negative and vice versa do occur. The present results suggest that these seroconversions are due to true changes in the antibody levels and not, for example, to technical variation or inaccuracy in the assays. ${ }^{47} \mathrm{It}$ has been pointed out that serial measurements of APF in longitudinal studies do not give more information than a single determination. ${ }^{17}$ In our study a statistically significant decline in the AFA levels was seen after starting DMARD treatment and a number of patiens reverted from positive to negative; some of these patients became positive again at a later stage. However, fluctuation of RF levels, as shown by reversals from positive to negative and vice versa, was appreciably greater than fluctuation of AFA levels. A feature common to RF and AFA was that the prevalence of positive reactions was highest at presentation; only a few cases negative at presentation became positive at a later phase. Our data on AFA cover only the first three years of the disease. Possibly, the fluctuation in AFA levels in advanced disease is less distinct than in the early phase. Another point that has to be taken into account is that we measured (in accordance with other authors) only AFA antibodies of IgG class, whereas the immunoturbidimetric $\mathrm{RF}$ test measures predominantly IgM class $\mathrm{RF}^{18}$

$\mathrm{RF}$ is the only immunological test for RA among the ARA 1987 classification criteria for RA. However, RF is neither uniformly present nor specific for RA. Thus there is a place for another diagnostic test for RA that is either more specific than tests for RF or is positive in a substantial proportion of RF negative patients with RA.

In the study described here the test for AFA proved to be somewhat less sensitive than that for RF. At entry to the study only a few RF negative patients were positive for AFA; after the start of DMARD treatment the proportion became larger. However, a fairly poor correlation was found even at entry between the levels of these two antibodies. Thus although both $\mathrm{RF}$ and AFA are markers of the same underlying immunological process of $\mathrm{RA},{ }^{19}$ they probably reflect different facets of the process and, hence, may complement each other.

The present series comprised patients in whom a firm diagnosis had been reached and DMARD treatment started soon after the onset of symptoms. The typical features of RA, however, may not always be present from the beginning and there can be a delay in the establishment of a firm diagnosis. Testing for AFA may provide useful information in cases initially presenting as undifferentiated arthritis. ${ }^{20}$ AFA levels also correlated with increased disease activity in these patients. However, they did not correlate with radiographic progression.

The antigen used in the AFA ELISA was prepared from human skin, thus the test is a useful reference for AFA assays that use other putative antigen substrates, such as heterologous or recombinant filaggrins or peptides corresponding to the filaggrin sequences. Recently, Schellekens et al, using synthetic peptides, provided evidence that citrulline, a post-translationally modified arginine residue, is an essential constituent of antigenic determinants recognised by antibodies reacting with filaggrin. ${ }^{11}$

1 Kingsley G, Panayi GS. Joint destruction in rheumatoid arthritis. Clin Exp Rheumatol 1997;15(suppl 17):3-14.

2 Aho K, Palosuo T, Kurki P. Marker antibodies of rheumatoid arthritis: diagnostic and pathogenetic implications. Semin Arthritis Rheum 1994;23:379-87. 
3 Paimela L, Gripenberg M, Kurki P, Leirisalo-Repo M. Antikeratin antibodies: diagnostic and prognostic markers for early

4 Cordonnier C, Meyer O, Palazzo E, de Bandt M, Elias A, Nicaise $P$, et al. Diagnostic value of anti-RA33 antibody, antikeratin antibody, antiperinuclear factor and antinuclear antibody in early rheumatoid arthritis: comparison with rheumatoid factor. Br J Rheumatol 1996;35:620-4.

5 Berthelot J-M, Maugars Y, Castagné A, Audrain M, Prost A. Antiperinuclear factors are present in polyarthritis before ACR criteria for rheumatoid arthritis are fulfilled. Ann Rheum Dis 1997;56:123-5.

6 Simon M, Gibral E, Sebbag M, Gomès-Daudrix V, Vincent C, Salama G, et al. The cytokeratin filament-aggregating protein filaggrin is the target of the so-called 'antikeratin antibodies', autoantibodies specific for rheumatoid arthritis. J Clin Invest 1993;92:1387-93.

7 Sebbag M, Simon M, Vincent C, Masson-Bessière C, Girbal E, Durieux JJ, et al. The antiperinuclear factor and the so-called antikeratin antibodies are the same rheumathe so-called antikeratin antibodies are the same rheumatoid arth $2672-9$.

8 Palosuo T, Lukka M, Alenius H, Kalkkinen N, Aho K, Kurki $\mathrm{P}$, et al. Purification of filaggrin from human epidermis and measurement of antifilaggrin antibodies in sera from patients with rheumatoid arthritis by an enzymelinked immunosorbent assay. Int Arch Allergy Immunol 1998; 115:294-302.

9 Vincent C, Simon M, Sebbag M, Girbal-Neuhauser E, Durieux J-J, Cantagrel A, et al. Immunoblotting detection of autoantibodies to human epidermis filaggrin: a new diagnostic test for rheumatoid arthritis. J Rheumatol 1998; 25:838-46

10 Slack SL, Mannik M, Dale BA. Diagnostic value of antibodies to filaggrin in rheumatoid arthritis. J Rheumatol 1998;25:847-51.

11 Schellekens GA, de Jong BAW, van den Hoogen FHJ, van de Putte LBA, van Venrooij WJ. Citrulline is an essential con- stituent of antigenic determinants recognized by rheumatoid arthritis-specific autoantibodies. J Clin Invest 1998; toid arthritis-

12 Paimela L, Palosuo T, Leirisalo-Repo M, Helve T, Aho K. Prognostic value of quantitative measurement of rheumatoid factor in early rheumatoid arthritis. Br J Rheumatol 1995;34:1146-50

13 van Gestel AM, Prevoo MLL, van't Hof MA, van Rijswijk $M H$, van de Putte LBA, van Riel PLCM. Development and validation of the European league against rheumatism response criteria for rheumatoid arthritis. Arthritis Rheum 1996;39:34-40

14 Larsen A, Dale K, Eek M. Radiographic evaluation of rheumatoid arthritis and related conditions by standard reference films. Acta Radiol Diagn 1977;18:481-91.

15 Nykänen $M$, Palosuo T, Aho K, Sahi T, von Essen R. Improved immunoturbidimetry for rheumatoid factor testing. J Clin Pathol 1993;46:1065-6.

16 Pham B, Crannaey A, Boers M, Verhoeven AC, Wells G, Tugwell $P$. Validity of area- under-the-curve analysis to Tugwell P. Validity of area- under-the-curve analysis to summarize effect in rheumato

17 Kerstens PJSM, Boerbooms AMT, Jeurissen MEC, Westgeest TAA, van Erp A, Mulder J, et al. Antiperinuclear factor and disease activity in rheumatoid arthritis. Longitudinal evaluation during methotrexate and azathioprine therapy. J Rheumatol 1994;21:2190-4.

18 Ailus K, Melamies L, Tuomi T, Palosuo T, Aho K. Measuring rheumatoid factor in nonrheumatoid subjects: immunoturbidimetric assay, latex slide test and enzymelinked immunosorbent assay compared. Clin Chem 1991;36:1766-9.

19 Aho K, von Essen R, Kurki P, Palosuo T, Heliövaara M. Antikeratin antibody and antiperinuclear factor as markers for subclinical rheumatoid disease process. J Rheumatol 1993;20:1278-81.

20 Aho K, Palosuo T, Lukka M, Isomäki H, Kautiainen $H$, von Essen R. Antifilaggrin antibodies in recent-onset arthritis. Scand J Rheumatol 1999;28:113-16. 